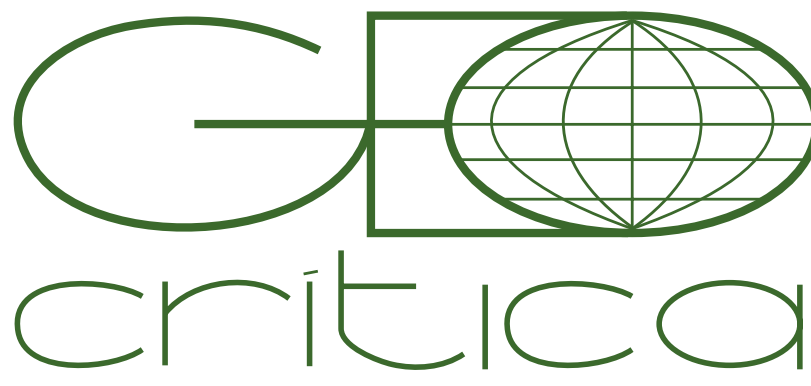

\section{Scripta Nova}

Revista Electrónica de Geografía y Ciencias Sociales Universitat de Barcelona

15 de mayo de 2018

\title{
SOSTENIBILIDAD DEL MEDIO RURAL Y PATRIMONIO INMATERIAL: A PROPÓSITO DE LOS CONOCIMIENTOS TRADICIONALES DE LAS PLANTAS
}

\author{
Eloy Gómez-Pellón \\ Universidad de Cantabria \\ gomezel@unican.es
}

Recibido: 25 de agosto de 2017; Devuelto para revisión: 23 de noviembre de 2017; Aceptado: 18 de febrero de 2018

\section{Sostenibilidad del medio rural y patrimonio inmaterial. A propósito de los conocimientos tradicionales de las plantas (Resumen)}

El conocimiento de las propiedades de las plantas, y los usos asociados a las mismas con fines muy diversos, ha formado parte del bagaje tradicional de las poblaciones rurales y ha jugado un importante papel en la sostenibilidad ambiental, social y económica de las mismas. Existen sobradas pruebas de que se trata de un valioso patrimonio cultural, con un fuerte componente inmaterial, que corre el riesgo de perderse definitivamente. Los motivos se hallan en la presión ejercida por un poderoso cambio social, consecuente con un creciente fenómeno urbanizador y con una globalización amenazante para la existencia de las culturas locales. En el caso de España, la imperiosa necesidad de proteger este patrimonio ha conducido a la adopción de medidas de muy diverso alcance que se repasan en el artículo.

Palabras clave: sostenibilidad, patrimonio cultural inmaterial, conocimientos medioambientales, conocimiento tradicional de las plantas, nueva ruralidad.

\section{Sustainability of the rural environment and intangible heritage: traditio-} nal knowledge of plants. (Abstract)

Awareness of the properties of plants and the diverse uses associated with them has formed part of the traditional store of knowledge of rural populations, and has played an important role in their environmental, social and economic sustainability. There is more than enough evidence that this valuable heritage, with its large intangible component,

Proyecto CSO201568696-P (MINECO/FEDER) "Cambios sociales y mundos de vida rurales: hacia la sostenibilidad social y la cohesión territorial. Programa Estatal de Excelencia I+D (2016-2018) is in danger of being lost forever. The reasons can be found in the pressure exercised by far-reaching social change, consistent with an expanding phenomenon of urbanisation and globalisation that is endangering local cultures. In the case of Spain, the pressing need to protect this heritage has led to the application of a wide range of measures, which are summarised here.

Keywords: sustainability, intangible cultural heritage, environmental knowledge, traditional plant lore, new rurality. 
El presente trabajo tiene por objetivo analizar los problemas que recaen sobre los conocimientos ambientales de carácter tradicional relativos a las plantas, que se hallan en posesión de las poblaciones rurales, integrando un vasto patrimonio inmaterial que ha contribuido de manera muy notable al desarrollo sostenible del medio rural, en el sentido con que fue formulado este concepto en 1987 por el Informe Brundtland, y en el mismo con el que cristalizó en la Conferencia de las Naciones Unidas sobre Medio Ambiente y Desarrollo, celebrada en Río de Janeiro en 1992, en su triple dimensión ambiental, social y económica. Se trata, en este caso, de conocimientos y de prácticas sedimentados en el transcurso del tiempo, y transmitidos a través de una larga secuencia de generaciones, referidos a plantas silvestres curativas, aromáticas, condimentarias, combustibles, ornamentales y de otros tipos que se hallan indefectiblemente unidos a la vida rural. Sin embargo, los intensos procesos de modernización y cambio social que se han producido han supuesto la pérdida progresiva de la actividad agraria y, complementariamente, el surgimiento de nuevas formas de entender la vida rural, esto es, de nuevas ruralidades que ya no son herederas de una inveterada tradición sino un producto de la modernidad tardía, en la cual el individuo ha roto los lazos con la comunidad y con la historia. La hipótesis de la que se parte en este trabajo es que estos conocimientos y prácticas se producían en un contexto social que alimentaba su conservación, el cual en el presente se halla por lo general periclitado, incluso en sociedades mediterráneas que, como la española, fueron refractarias a los procesos de modernización cultural durante la primera mitad del siglo XX, con la consiguiente ruptura de la transmisión intergeneracional y con los riesgos que le son inherentes, entre los cuales no es menor el de la apropiación de tales conocimientos y prácticas por agentes externos.

Los trabajos realizados en nuestro país en los últimos años acerca de los conocimientos y usos relacionados con las plantas prueban el interés de los mismos, aunque también la preocupación por la alarmante pérdida que los afecta. En este sentido, las ciencias sociales no han sido remisas a estudiar los principios que rigen en las diferentes culturas, a propósito de la selección y aprovechamiento de las plantas, como se evidencia en el caso de la antropología social. Algunas corrientes antropológicas, como las postestructuralistas, y de modo relevante la llamada etnociencia o etnosemántica, han adoptado paradigmas cognitivos, mediante los cuales han tratado de mostrar cómo los seres humanos perciben la naturaleza, en general, valiéndose de reglas finitas que se hallan inscritas en las culturas de los seres humanos. Estas reglas alimentan una especie de gramática cultural, que ha sido muy bien estudiada por B. Berlin', W. Goodenough ${ }^{2}$, S. Tyler ${ }^{3}$ y otros. Precisamente, el primero de los mismos se ha ocupado muy específicamente de todos los aspectos ligados a la cognición de las plantas por parte de los grupos humanos.

\footnotetext{
1 Berlin, 1992.

2 Godenough, 1975.

3 Tyler, 1969.
} 
Junto a esta perspectiva cognitiva se halla otra que podemos denominar utilitarista, que trata de descubrir las técnicas de uso y manejo que los seres humanos llevan a cabo en su interacción con las plantas, la mayor parte de las veces por razones prácticas, las cuales a su vez son indisociables de los aspectos simbólicos. Esta última perspectiva, especialmente a través de la etnobotánica, ha alcanzado un gran desarrollo en nuestro país ${ }^{4}$, en concordancia con el que se ha producido en este ámbito científico. Al lado de la etnobotánica, otras disciplinas se ocupan de los aspectos utilitarios de las plantas, tales como, por ejemplo, la farmacología, la fitoterapia, la botánica, la ecología y otras, incluidas las que lo hacen desde la perspectiva de las ciencias sociales, como la antropología, la sociología y la geografía. Creemos que resultaría reduccionista aislar una parte de las motivaciones que mueven al ser humano a relacionarse con las plantas porque, al tratarse de un entramado de aspectos concurrentes, renunciaríamos a la comprensión total del fenómeno. Sin embargo, no dudamos de que el hecho de focalizar con mayor intensidad un aspecto determinado, sin perder de vista los demás, puede resultar ventajoso, según las necesidades, desde el punto de vista científico.

De hecho, el abordaje del fenómeno que representa el conocimiento de los usos de las plantas por parte de las poblaciones rurales debe ser multidisciplinar, tal como se ha reclamado reiteradamente ${ }^{5}$. La concurrencia de disciplinas distintas en un mismo objeto de estudio, a fin de aprehender el corpus de conocimientos y de prácticas que se ha ido construyendo a lo largo del tiempo, en uno o varios entornos geográficos, mediante procedimientos adaptativos resultantes del encuentro de la naturaleza y la cultura ${ }^{6}$, puede proporcionar buenos resultados. La existencia de estos procedimientos adaptativos es inseparable de un fuerte componente tradicional, con innovaciones de diverso signo que se van introduciendo gradualmente. Estas innovaciones, que en el pasado eran resultado de la interacción entre personas residentes en entornos cercanos, en la actualidad, y ésta es una de las grandes novedades, son la consecuencia de interacciones de alcance universal, generalmente guiadas por intereses ajenos a la vida de las poblaciones rurales, como pueden ser los empresariales, tal como veremos más adelante, con la consiguiente pérdida del acervo cultural y de la propia identidad de estas poblaciones. Los estudios científicos tampoco escapan de estos intereses, lo cual explica que muchos de ellos se orienten exclusivamente a las aplicaciones prácticas del conocimiento y usos de las plantas, prescindiendo de la necesaria contextualización cultural.

El hecho de que los mencionados procesos de cambio alcancen, en distinto grado, a la totalidad de los espacios rurales europeos, y aun considerando que en los mediterráneos presentan caracteres propios, no oculta que se trata de una trasformación que, en lo sustancial, no es diferente de la que se está produciendo en todo el mundo, debido a los efectos de la globalización, y a la concurrencia de factores

4 Pardo de Santayana y Gómez Pellón, 2003; Morales et al., 2011; Pardo de Santayana et al., 2012; Molina et al. 2012; Pardo de Santayana, 2014; Pardo de Santayana y Macía, 2015.

5 Vid. por ejemplo, Pardo de Santayana y Gómez Pellón, 2003; Drew y Henne, 2006.

6 Vid. Descola, 20005. 
como la creciente urbanización y la desagrarización, todo lo cual sugiere la adopción de un punto de vista amplio en este trabajo, que permita tomar en consideración la existencia de una gran variedad de casos particulares. Partiendo de la hipótesis señalada anteriormente, y por las razones aludidas, se adoptará una metodología comparativa, de carácter cualitativo, que, focalizando preferentemente el caso español, observe la presencia de analogías en otros contextos. Junto con la bibliografía especializada y las fuentes normativas, se emplearán fuentes primarias, procedentes del trabajo de campo del autor en el norte de España, realizado en una secuencia temporal dilatada, que abarca la última década del siglo XX y el tiempo transcurrido del siglo XXI, así como fuentes primarias manejadas por otros autores, debidamente contrastadas, siempre que incorporen un aparato descriptivo que resulte acorde con el objetivo general que se ha trazado en este mismo apartado.

El artículo se organiza en cuatro apartados que toman como referencia el caso español. En el primero se examina la contribución de las poblaciones rurales a la utilización sostenible de un gran número de plantas en los más variados ecosistemas, gracias a la puesta en práctica de unos conocimientos transmitidos oral y empíricamente entre generaciones, los cuales constituyen hoy un valioso patrimonio inmaterial. En el segundo apartado se explica cómo este patrimonio inmaterial, sensible por definición, se halla sujeto a graves riesgos, debidos al profundo cambio social que se está produciendo en el medio rural. En el tercer apartado se analizan las soluciones que se han encontrado hasta el presente para hacer frente a la pérdida de conocimientos tradicionales, por ejemplo haciéndolos valer como derechos de la propiedad intelectual, o recurriendo a sofisticados sistemas codificados y no codificados. En el último apartado se valoran los distintos mecanismos de protección que se han activado en España, considerando que los conocimientos tradicionales acerca de las plantas representan un patrimonio susceptible de ser eficazmente inventariado, al menos a efecto de salvaguardia.

\section{Conocimientos y usos tradicionales relacionados con las plantas}

La información que poseemos en el presente sobre el conocimiento popular de las plantas y sus usos es aún modesta, por comparación con lo que sucede en algunos países de nuestro entorno, y no es exagerado decir que insuficiente. Además, los condicionamientos que recaen sobre la obtención de esta información recomiendan no demorar la tarea. En la España interior se ha producido un vaciamiento de las áreas rurales, al igual que el que ha tenido lugar en las zonas de montaña de las regiones costeras, con la consiguiente pérdida de un valioso patrimonio agrario que bien pudiera ser contemplado como una categoría unitaria ${ }^{7}$. El despoblamiento y el envejecimiento de la población son factores que se oponen a la conservación de estos conocimientos y prácticas relativos a las plantas. Pero no son los únicos factores adversos, puesto que la transformación que se ha producido en las últimas décadas en las actividades económicas del mundo rural constituye un importante obstáculo

7 Castillo y Martínez, 2014. 
para el mantenimiento de los tradicionales conocimientos y prácticas ambientalistas. Por ejemplo, los cambios en los aprovechamientos forestales, en favor de la explotación de especies especulativas, suponen una fuente de dificultades para la recolección de plantas silvestres, e incluso la imposibilidad de realizarla. Por otro lado, los nuevos usos agrarios, que incluyen tanto la introducción de nuevos cultivos como la modificación de los ciclos vegetativos de las especies tradicionales, y, en su caso, la reducción de las áreas de cultivo, con el correspondiente avance del matorral, introducen grandes inconvenientes, a veces insalvables, en la recolección de las plantas silvestres que crecen en los linderos de la tierra labrada, las cuales han venido siendo objeto de recolección tradicional en primavera y en otoño. Estos cambios en los usos agrarios no sólo alcanzan a los espacios agrícolas sino también a los ganaderos. Los aprovechamientos de pastos en las áreas montañosas a menudo se han convertido en simple remedo, pero los aprovechamientos pratenses corren la misma suerte en muchos lugares, debido a la pérdida de importancia de la economía ganadera.

Las áreas rurales han sido, hasta el presente, las encargadas de la conservación y utilización sostenible de un gran número de plantas, gracias a unos conocimientos suministrados, fundamentalmente, por la tradición popular ${ }^{8}$. La mayor parte de los ecosistemas terrestres son el producto de una antropización, llevada a cabo en mayor o menor grado, y sostenida en el tiempo. Las maneras de actuar del ser humano sobre estos ecosistemas son muy variadas. En ocasiones, la acción antrópica se reduce a la mera recolección, mientras que, en el extremo contrario, es llevada a cabo mediante técnicas intensivas. La actividad recolectora contribuye a mejorar la biodiversidad, al igual que el resto de las actividades sostenibles, incluidas las propias de la producción agrícola y ganadera. Con cierta frecuencia se ha puesto como ejemplo de agroecosistema sostenible, enriquecedor de la biodiversidad, a la dehesa, en la cual, hasta comienzos de la segunda mitad del siglo XX convivieron en perfecta simbiosis aprovechamientos tan diversos como los relativos a la caza mayor y menor, a la recolección de frutos, semillas, hongos, hojas y plantas silvestres, al carboneo, a la recogida de leña, a la apicultura, a la explotación del corcho, a la extracción de la madera, a la agricultura extensiva, a la práctica de una ganadería extensiva y semiextensiva, de carácter heterogéneo, con atención a los requerimientos de especies como la bovina, la ovina la porcina y la caprina, todos los cuales formaban parte de una nómina interminable y equilibrada de usos y actividades. Con estas características, la dehesa ha sido un paisaje histórico, ejemplo de auténtica sostenibilidad, que ha proveído las necesidades de las poblaciones locales del occidente de la región castellano-leonesa, de la extremeña y de la andaluza durante muchos siglos. Tal como se acaba de señalar, la recolección no ha sido ajena y, muy al contrario, ha tenido una gran importancia, siendo un buen ejemplo la recolección de setas, pero también la de todo tipo de plantas medicinales, aromáticas, condimentarias, etc., convirtiendo a la dehesa en un modelo de explotación sostenible y

8 Cuisenier, 1995. 
equilibrado de los recursos naturales, que, sin embargo, en la actualidad se halla en franco retroceso?.

Otros agroecosistemas de nuestro país constituyen ejemplos, igualmente, del uso sostenible de los recursos vegetales. Es el caso de las tradicionales mieses y erías del norte de España, antiguos espacios agrarios de campos abiertos, en los cuales han convivido históricamente los aprovechamientos agrícolas y los ganaderos con otros usos, como los propios de la recolección de las plantas silvestres en los linderos y las servidumbres de paso ${ }^{10}$. Igual que los montes comunales, y de la misma manera que en los de mano común de Galicia, en los cuales ha sido posible hasta fecha reciente la explotación de los recursos forestales, frugívoros (castañas, bellotas, etc.), y también ganaderos, gracias el pasto del sotobosque, juntamente con la recolección de plantas silvestres, el carboneo y la recogida de leñas, de hojas y de plantas combustibles. Un ejemplo más de ecosistemas sostenibles lo encontramos en los puertos de la cordillera Cantábrica, cuyo pasto fresco ha sido tradicionalmente aprovechado por los ganados, en régimen de estivage, entre finales de la primavera y comienzos del otoño, y donde estas actividades de pastoreo se conjugan con el uso de madera para la artesanía o con la recogida de plantas silvestres, como el té del puerto o la manzanilla, entre otras muchas. La actividad antrópica es la clave que nos permite entender la conservación de los paisajes agrarios y el uso sostenible de la biodiversidad a lo largo del tiempo. El buen manejo que se ha hecho del fuego en muchos de estos lugares, y del agua en su caso, ha contribuido al eficaz aprovechamiento de los recursos en estos ecosistemas.

Ciertamente, el conocimiento y el buen uso de las plantas han propiciado excelentes ejemplos de aprovechamiento continuado y sostenible de especies vegetales, que en el presente se hallan en riesgo de extinción por razones ajenas a la práctica tradicional. De ello dábamos cuenta, hace algunos años, a propósito de las acebedas ${ }^{11}$. Estos conjuntos de acebos proporcionaban sombra al ganado durante el verano, y resguardo del frío y la lluvia durante el invierno en numerosas áreas montañosas de nuestro país. El hecho de que se trate de árboles de hoja perenne constituía una garantía de aprovechamiento comestible por el ganado durante todo el año, y, al mismo tiempo, proveían de soluciones prácticas para los humanos de forma permanente. El empleo indiscriminado de estos árboles, trascendiendo los usos que les fueron propios en el pasado, como por ejemplo el empleo decorativo durante la Navidad, ha aconsejado la producción de una rígida normativa protectora.

Los numerosos trabajos de campo llevados a cabo en el área cantábrica, en Castilla y León, en Extremadura, en Andalucía, en el área mediterránea, en Aragón, en el País Vasco, y, en general, en toda España, prueban la importancia que aún tiene la recolección de plantas silvestres y sus muchas aplicaciones. Lo mismo se pone de manifiesto en los trabajos realizados en otras partes de la Península Ibérica, como se

9 Pérez Díaz, 2005 y 2015; Llorente Pinto, 2011; Silva Pérez, 2010.

10 Gómez Pellón, 1994.

11 Pardo de Santayana y Gómez Pellón, 2003. 
muestra en el realizado por Frazäo-Moreira, Carvalho y Martins en Tras-os-Montes, en el nordeste interior de Portugal, en las inmediaciones de la raya zamorana ${ }^{12}$. Al igual que se evidencia en las investigaciones llevadas a cabo en distintas áreas rurales españolas, en el caso de Quintanilha, un pequeño pueblo de Trás-os-Montes, éste se halla entre un pasado campesino y el horizonte de una nueva ruralidad, muy alejada de la tradicional, dominada por una manera diferente de vivir y sentir el campo, en la cual múltiples actividades, ajenas a la agraria, conviven con esta última, reducida por lo general a la mínima expresión. En otras áreas mediterráneas, aún más resistentes al cambio social que las ibéricas, se ha producido una transformación análoga en muchos aspectos, como se deduce del reciente trabajo de A. Pieroni y R. Soukand ${ }^{13}$ sobre el nordeste de Albania. Como he tenido ocasión de explicar en otro lugar, en la nueva ruralidad ${ }^{14}$ la vida en el campo alberga modos de vida muy diferentes, en ocasiones sin vínculo con el medio físico, y, sobre todo, gentes con estilos de vida en los cuales la residencia en el medio rural puede ser accesoria, y la apropiación de la naturaleza puede ser llevada a cabo de forma individualizada, sin necesidad de compartir un fondo colectivo de conocimientos ambientalistas que, en el mundo rural del pasado, era adquirido generalizadamente mediante la socialización tradicional. Acaso estos cambios expliquen la intensa transformación que se está produciendo en el conocimiento y en las prácticas relacionadas con el uso de las plantas silvestres en todas las regiones españolas, como se percibe en la reciente investigación llevada a cabo en el País Vasco por Méndez-Baceta ${ }^{15}$ y colaboradores, donde la identidad cultural contribuyó con firmeza a la conservación de estas costumbres hasta hace muy poco tiempo.

El texto publicado por Pardo de Santayana y por el autor del presente texto ${ }^{16}$ ponía de manifiesto, hace algunos años, cómo las poblaciones rurales de la comarca de Campoo, en Cantabria, han empleado tradicionalmente, con distintos fines, un dilatado repertorio de plantas, en su mayoría silvestres, el cual sigue siendo conocido al menos por una parte de sus habitantes, ciertamente que cada vez más reducida. Algunas de estas especies silvestres eran apreciadas, por ejemplo, por su carácter comestible. Los estudios llevados a cabo en los últimos años en regiones como Cataluña y Madrid revelan que las partes preferentemente comestibles de estas plantas son las hojas y los tallos, aunque en un porcentaje importante también lo son los frutos y las semillas ${ }^{17}$. Sin embargo, el estudio etnobotánico sobre la comarca cántabra de Campoo ${ }^{18}$, confirmando la existencia de un gran número de plantas comestibles por parte de las poblaciones locales, nos descubre que en esta área son los frutos y las semillas las partes comestibles más habitualmente consumidas. Además,

12 Frazäo-Moreira, Carvalho y Martins, 2007.

13 Pieroni y R. Soukand, 2017.

14 Gómez Pellón, 2014, y Gómez Pellón, 2015.

15 Méndez-Baceta, 2017.

16 Pardo de Santayana y Gómez Pellón, 2003.

17 Morales et al., 2011.

18 Pardo de Santayana, 2008. 
las poblaciones rurales de las áreas señaladas han venido encontrando en las setas un recurso comestible, propio de la primavera y del otoño, altamente valorado. Esta favorable valoración de las setas alcanza a las poblaciones urbanas aledañas, lo cual explica que una parte de la recolección se destine a los mercados de las villas y ciudades cercanas, donde las setas alcanzan precios muy elevados que contribuyen a mejorar los resultados de las explotaciones familiares.

El conocimiento de las plantas también ha contribuido al uso de las mismas con fines curativos. Tal vez sea ésta, en la actualidad, la aplicación que despierta un mayor interés por razones prácticas, las cuales, a su vez, constituyen también un objetivo relevante para la investigación científica. Son plantas que, desde tiempo inmemorial, han sido destinadas al tratamiento de las enfermedades humanas y las animales. Pardo de Santayana ${ }^{19}$ ha hallado 45 plantas que siguen empleándose en nuestros días en el área cantábrica, concretamente en el sur de Cantabria, en la comarca de Campoo. Muchas de ellas son habituales en los sistemas montañosos de toda la Península Ibérica. Las sumidades floridas, las hojas, los frutos y las partes aéreas han sido usadas con más frecuencia en la preparación de productos curativos, las más de las veces mediante cocción y hervido, pero también mediante simple calentamiento o a través del macerado, e, incluso, directamente, sin preparación previa, en la curación de las afecciones más diversas de las vías respiratorias, del aparato digestivo, del sistema circulatorio, del aparato urinario, del reúma, del sueño, etc. En la cordillera Cantábrica son bien conocidas las diferentes variedades de té silvestre, manzanilla, cardo, espliego, hierba luisa, árnica, hiedra, cardo, badana, malva, hierbabuena, orégano, tomillo, romero, saúco, menta, anís, etc. Las aplicaciones prácticas de estas plantas incluyen la elaboración de infusiones, ungüentos, pomadas, bálsamos, etc.

Tanto en mi estudio sobre un valle asturiano ${ }^{20}$ como en mi trabajo etnográfico sobre un pueblo de Cantabria, en el valle del $\mathrm{Nansa}^{21}$ pude mostrar la importancia del conocimiento de la madera en la elaboración de los útiles de la vida cotidiana, cuyos conocimientos y aplicaciones aún no han sido desplazados por entero en el presente. Efectivamente, en la vida tradicional una gran parte de los útiles empleados en la actividad agraria era de madera, pero también en la vida doméstica, y éste era el caso de numerosos recipientes, platos, escudillas, cucharas, etc., así como el del calzado de las áreas húmedas de nuestro país, a menudo elaborado con madera de alisa, de haya, de abedul, etc., y hasta los instrumentos musicales empleados en el tiempo de ocio, Por supuesto, una gran parte de la construcción de la casa se realizaba con madera, incluyendo forjados, puertas, ventanas, balconadas, etc. Todo ello suponía un buen conocimiento de la foresta, de manera que según la fabricación requiriera un determinado grado de robustez, o de dureza, o un mayor o menor peso, las maderas empleadas eran diferentes. Así se conjugaba el uso de maderas de

19 Pardo de Santayana, 2008.

20 Gómez Pellón, 1994.

21 Gómez Pellón, 1998. 
una gran dureza, como el ácere, el boje, la encina, o el roble, que subvienen a usos inmarcesibles, pero que se trabajan con una gran dificultad, con maderas, relativamente duraderas pero de una apreciable blandura, procedentes, generalmente, del bosque de ribera, como la alisa o el avellano. Pardo de Santayana ${ }^{22}$ ha examinado muchas de estas utilidades en la vida tradicional de las poblaciones de la comarca de Campoo, por ejemplo en el caso de la elaboración de escobas, mediante el uso del brezo, del abedul, del avellano, de la palma y de otros. Conocida ha sido también la importancia de algunos vegetales en la elaboración de contenedores de cestería, realizados con madera de avellano, de mimbre, de sauce, etc., tan propios y característicos de la vida tradicional.

Pero las plantas del bosque proveían, además, del alimento que consumía el ganado en algunas épocas del año. En la cordillera Cantábrica la hoja del bosque era muy apreciada en algunos períodos estacionales, como el otoño y el invierno, en los cuales faltaba la cubierta herbácea que servía a la guadaña y al pasto. Eran los meses en los que el ganado consumía la hoja perenne de los encinares y los carrascales, de las acebedas, y de otras plantas, como la hiedra. Durante el resto del año, y según la oportunidad, el ganado se nutría con la hoja de robledales, olmedos, choperas, fresnedos, etc. La estrategia del rebaño heteróclito permitía optimizar el alimento que proporcionaba la hoja de los árboles. Mientras que algunos ganados, como el caprino y el ovino, comían las hojas más duras, el ganado bovino consumía las hojas más tiernas de las diferentes especies vegetales.

No han sido pocas las plantas que se han venido empleando como combustible, algunas de las cuales resultaban muy apreciadas por su excelente ignición, como el carrasco. Ni las que se usaban con fines aromáticos, o las que se destinaban a la ornamentación en las fiestas, como las del domingo de ramos (laureles, tejos, palmeras, etc.), o los saúcos de la noche de San Juan en el norte de España. En fin, todo ello prueba la importancia que tuvieron en la sociedad tradicional los conocimientos y los usos de plantas, los cuales han sido incorporados, de manera desigual y en grados muy diversos, a las sociedades modernas. Sin embargo, el cambio social y económico que se ha producido en el medio rural, y las modernas alternativas surgidas frente a los conocimientos y los usos tradicionales, han terminado por poner en riesgo la transmisión cultural.

En el trabajo suscrito por Pardo de Santayana y Gómez Pellón ${ }^{23}$ se recordaba cómo las especies silvestres que se emplean con fines utilitarios en España son alrededor de 1700, que representan, aproximadamente, algo menos de la cuarta parte de las especies de flora silvestre conocidas en nuestro país. Los estudios llevados a cabo en los últimos años no han modificado apenas estos porcentajes, aun teniendo en cuenta el progreso que se ha producido en este ámbito del conocimiento científico. El patrimonio que comporta el conocimiento teórico y práctico de las plantas por parte de las poblaciones rurales abona la necesidad de protegerlo. El hecho de que

22 Pardo de Santayana, 2008.

23 Pardo de Santayana y Gómez Pellón, 2003. 
tan sólo se haya conservado, en general, por razones de autoconsumo o, simplemente, de entretenimiento, revela el riesgo que se cierne sobre este patrimonio. Aunque pudiéramos pensar que una de las formas de conservación podría venir dada por la domesticación de estas plantas mayoritariamente silvestres, conviene recordar, en primer lugar, que los intereses empresariales sólo recaerían sobre una parte menor de estas plantas y no sobre aquéllas cuya rentabilidad económica resultara dudosa y, en segundo lugar, que razones de índole mercantil hacen que las plantas cultivadas procedan, a menudo, de ecotipos genéticamente mejorados, de carácter exógeno, las cuales competirían con la las variedades endógenas que podrían situarse en clara desventaja.

\section{El mercado de los comunes}

Más arriba se han mostrado los riesgos inherentes a la pérdida de conocimientos y prácticas relativos a las plantas, por razones diversas, y que básicamente se refieren al despoblamiento y al envejecimiento de la población en las áreas rurales, de lo cual se sigue la ruptura intergeneracional y la interrupción de la inherente cadena en la transmisión de información. En muchos lugares del medio rural español falta la necesaria juventud que garantice el reemplazo generacional en las actividades más vinculadas a la vida en estos espacios y, por ello, la conservación de los conocimientos tradicionales ligados al medio físico. La pérdida de estos conocimientos representa una amenaza importante para la sostenibilidad ambiental, social y económica de las áreas rurales. Los caracteres derivados de la masculinización de los habitantes de las áreas rurales constituyen una dificultad añadida para conservar los tradicionales conocimientos ambientalistas, y, a propósito de este trabajo, orientados a la recolección de las plantas y a su aplicación práctica. Así, se da la circunstancia, y como tal lo prueban los trabajos de campo del autor de este trabajo ${ }^{24}$, de que muchos de estos conocimientos han sido, preferentemente, patrimonio femenino, de suerte que los mismos eran recibidos acumulativamente a lo largo de la vida de las personas, lo cual contribuye a explicar que sean las mujeres ancianas las expertas en el uso de las plantas silvestres curativas, aromáticas, condimentarias, etc., mientras que el conocimiento de los hombres basculaba sobre las plantas destinadas a la alimentación del ganado, los usos artesanales, los combustibles y algunos otros.

Ahora bien, estos riesgos endógenos, inherentes a la propia evolución interna de las poblaciones rurales, se complementan con otros que podemos llamar exógenos, esto es, generados desde fuera. Sabida es la importancia que ha adquirido el fenómeno de la globalización en los últimos lustros en todo el mundo, no porque éste sea de origen reciente, sino porque sus efectos se han intensificado extraordinariamente tras la incorporación a los circuitos mercantiles de enormes espacios políticos que antes se hallaban fuera del gran comercio internacional, como la antigua Unión Soviética, juntamente con su área de influencia, y China. La globalización implica interdependencia entre las sociedades en todos los ámbitos, incluidos los culturales

24 Por ejemplo, Gómez Pellón, 1994 y 1998. 
y los económicos, con ayuda de las comunicaciones y las nuevas tecnologías de la información. El trabajo, antes referido, de Frazäo-Moreira, Carvalho y Martins ${ }^{25}$, aprecia una importante influencia de las televisiones españolas al otro lado de la raya, en el área fronteriza de Tras-os-Montes, hasta el extremo de que los consejos de los programas de salud han terminado por alcanzar a las costumbres que regían los conocimientos y las aplicaciones de las plantas en el área rural que fue objeto de estudio por parte de estos investigadores. En realidad, este efecto propiciado por las comunicaciones televisivas constituye una parte de otro más general que alcanza, acaso con mayor intensidad, a las modernas redes de Internet, análogamente a lo que sucede en cualquier parte del mundo. Por supuesto, estos flujos de la información, muy intensos en el ámbito informático y telemático, a veces conectados con intereses mercantiles, interfieren en los usos tradicionales que las poblaciones rurales han venido llevando a cabo. Mientras que en el pasado estos conocimientos tenían un carácter particular, y venían dados por el entorno local, en la actualidad el proceso globalizador homogeneiza los conocimientos de las plantas y los usos, confiriendo a los mismos un carácter general que trasciende el medio natural de una población determinada.

Curiosamente, en el caso que nos ocupa, esto es, en el de las plantas, la difusión a escala planetaria comenzó antes que en ningún otro ámbito. Desde finales del siglo XV el trasvase de plantas entre América y Europa fue extraordinario, y a la inversa sucedió lo mismo, correspondiéndole a España un papel de intermediación que resultó decisivo, como bien han explicado J. M. López Piñero y M. L. López Terrada ${ }^{26}$. Asia no fue ajena a este intercambio, en el cual el cultivo de las plantas trascendió las viejas fronteras en las que éstas se hallaban enclaustradas. De hecho, en América surgieron los primeros monocultivos comerciales de la historia. En esta misma época, y simultáneamente, algunos mercados como el de las especias destinadas al consumo alcanzaron dimensiones planetarias, y su consumo constituye uno de los mejores ejemplos del rápido progreso del llamado sistema mundial. Fue de este modo cómo la canela, la vainilla, el clavo, el jengibre, la nuez moscada, el cardamomo, el azafrán o la vainilla de Jamaica, entre otras muchas, alimentaron progresivamente un comercio mundial27. Pero el mismo ejemplo que nos suministran las plantas empleadas a escala planetaria en el condimento nos lo facilitan, igualmente, las plantas estimulantes, como el té, el café y el cacao, también en la misma época, y las plantas edulcorantes, como la caña de azúcar. Unas y otras pasan en un breve espacio de tiempo de ser desconocidas en Europa a ser de uso cotidiano en las sociedades urbanas e, inmediatamente después, en las rurales. Otras plantas foráneas no sólo se consumen, sino que son también cultivadas. La experiencia histórica nos muestra cómo, al tiempo que tienen lugar las grandes colonizaciones, muchas plantas son arrancadas de las comunidades locales de todos los continentes para ser aclimatadas

25 Frazäo-Moreira, Carvalho y Martins, 2007.

26 López Piñero y López Terrada, 1998.

27 Sánchez Pons, 2013. 
en distintas partes de la Tierra e, incluso, para ser confinadas en las áreas dedicadas a los monocultivos comerciales.

Es cierto que las plantas, expresión palmaria de la biodiversidad, han sido llevadas de un lado a otro de la Tierra en los últimos siglos, con fines económicos, hasta trasformar los paisajes agrarios. Sin embargo, muchas plantas, aquéllas que eran recogidas en estado silvestre, habían quedado al margen del trasiego comercial, acaso porque no se las había encontrado un rendimiento económico, más allá de la utilidad que pudieran tener para las comunidades locales. El hecho de que estas plantas no hayan sido domesticadas les confiere caracteres propios en cada lugar de la tierra, dados por la adaptación. La observación y el uso de tales plantas por parte de las poblaciones locales es lo que explica que sean apreciadas por razones prácticas y simbólicas, que difieren entre áreas geográficas relativamente cercanas. Una buena parte de estas plantas, por lo que se refiere a España, al igual que sucede en otros lugares de Europa ${ }^{28}$, y en este sentido es bien expresivo el reciente trabajo de Sansanelli y Tassoni ${ }^{29}$ sobre la Emilia Romana, han crecido, debido a su carácter silvestre, en espacios comunes, que, consecuentemente, no se hallaban adscritos a la titularidad individual. En otros casos, nacían dentro de espacios particulares, pero en áreas marginales de los mismos. La índole asilvestrada de estas plantas explica que se recolectaran muchas veces en los intersticios de las áreas cultivadas y, en general, en los espacios menos valorados.

Ahora bien, si hasta hace sólo unas décadas gran parte de los habitantes de las áreas rurales de todo el mundo encontraban la satisfacción de sus necesidades en los entornos locales, en el presente un porcentaje cada vez mayor la halla en el mercado. No cabe duda de que este fenómeno es más perceptible en los países occidentales, donde la actividad agraria se ha reducido a la mínima expresión y donde el proceso urbanizador ha sido incesante. A ello contribuyen también los medios de comunicación, que, con la ayuda de las nuevas tecnologías de la información, convierten al ciudadano en consumidor. Así, estos medios sugieren, por un lado, el consumo de plantas que no pueden ser satisfecho en los entornos locales, por tratarse de plantas exógenas introducidas a gran escala en los circuitos comerciales $\mathrm{y}$, por otro lado, estos mismos circuitos ponen al alcance de los consumidores, incluidos los rurales, plantas que, hallándose en los entornos locales de estos últimos, pueden ser adquiridas a bajo coste en un mercado global, provocando la renuncia a la recolección que venían realizando las poblaciones rurales de acuerdo con cánones tradicionales. Así se explica que nunca como en las últimas décadas las grandes corporaciones internacionales hayan competido tan denodadamente para hacerse con el comercio de la vida natural convertida en mercancía, cuyos orígenes, como se acaba de mostrar, son ya viejos en el caso de las plantas.

En la actualidad, frecuentemente, las grandes empresas internacionales se apoderan de los códigos genéticos de las plantas con objeto de comercializarlos, previa

28 Pardo de Santayana, Pieroni y Puri., 2010

29 Sansanelli y Tassoni, 2014. 
manipulación en su caso, y ya no sólo de plantas cultivadas sino también de plantas silvestres de comunidades locales de todo el mundo ${ }^{30}$. Esas plantas son comercializadas bajo determinadas marcas registradas sin que las comunidades locales en las que tienen origen obtengan el mínimo beneficio. Pero no sólo las plantas, sino también los conocimientos prácticos a ellas asociados se convierten en mercancía. Al mismo tiempo, esas plantas (en forma de raíces, de bulbos, de semillas, de hojas, etc.) y los usos que les son inherentes, son publicitados, mediante las modernas tecnologías de la comunicación, bajo los correspondientes sellos comerciales, y puestos a la venta en los comercios especializados. Por supuesto, la mercancía no sólo se beneficia de la publicidad a gran escala sino también de un precio lo suficientemente competitivo como para hacer olvidar a las poblaciones rurales sus viejas costumbres relativas a la recolección de las plantas. Valga el ejemplo de que en muchas áreas rurales ha desparecido en las últimas décadas la recolección tradicional de plantas silvestres, ante el efecto demoledor de la oferta comercial que se realiza a buen precio, a veces comercializando especies de plantas, conocimientos y usos, bajo marcas registradas, que son patrimonio de las comunidades rurales. En esta situación, los efectos que representaba para la sostenibilidad la recolección de las plantas silvestres están comenzando a ser simple remedo en muchas áreas rurales.

Desde hace algún tiempo la apropiación de conocimientos locales sobre las plantas por parte de empresas de todo tipo es un hecho común, y muy especialmente por lo que concierne a la industria farmacéutica, a la de la cosmética, a la de los perfumes y a otras. Se trata de una apropiación que ha sembrado la alarma en el mundo académico y en el científico, pero también en las comunidades indígenas, cada vez más sensibilizadas con los problemas asociados al hurto de conocimientos ambientales que les pertenecen. Esta sensibilización es, asimismo, cada vez más evidente en las sociedades rurales europeas, las cuales también reclaman la titularidad sobre sus tradicionales conocimientos ecológicos, sabedoras de que en los mismos puede residir una de las claves de su desarrollo rural. Un trabajo realizado hace algunos años por Reyes-García ${ }^{31}$ pone de manifiesto el hecho aducido reiteradamente de que el interés del conocimiento ecológico tradicional no se explica tan sólo por su posible utilidad, sino también por los aspectos simbólicos que llevan incorporados esos conocimientos.

Es bien sabido que todas las culturas tradicionales, sin distinción, hacen, o han hecho, uso de los conocimientos ambientalistas consuetudinarios en relación con las plantas, y el caso de las culturas rurales de nuestro país no es distinto. Es evidente, además, que vivimos un momento crucial. Por un lado, estos conocimientos acerca de las plantas, propios de las comunidades locales, están declinando como consecuencia del intenso proceso de cambio social que se viene produciendo desde mediados del siglo pasado. Por otro lado, el progreso científico en el ámbito bioteconológico y en el bioinformático, con aplicaciones sanitarias, industriales, agrarias y

30 Efferth et al., 2016.

31 Reyes-García, 2009. 
marinas, entre otras, alimenta el interés por los conocimientos y los usos tradicionales de las plantas. El hecho de que el conocimiento popular se base en suposiciones, locales o parciales, que pueden ser verosímiles, convierte a éste en una hipótesis para la investigación científica, sustentada por el contrario en resultados reiterados, universales y verificados. Dado que los altos costes motivados por la investigación sólo se recuperan mediante la inscripción de patentes de explotación, las empresas especializadas han venido entendiendo estos conocimientos populares como dominio público, de suerte que salvan por esta vía cualquier posible obligación de restitución a las comunidades locales.

\section{Propuestas frente al riesgo de usurpación}

La recolección de plantas silvestres concita numerosas ventajas, tanto para el ser humano como para la naturaleza. Para el primero supone disponer de principios activos de gran utilidad para su particular bienestar, en ámbitos tan diversos de su vida cotidiana como el medicinal y el condimentario, entre otros muchos. En relación con la naturaleza, la recolección de estas plantas contribuye a la fijación de poblaciones vegetales en su medio natural y al estímulo de la biodiversidad, convirtiéndose en uno de los fundamentos de la sostenibilidad ambiental que, en consecuencia, se conjuga con otras sostenibilidades, como la social y la económica. La recolección tradicional implica un aprovechamiento moderado de estos recursos silvestres, evitando que resulten esquilmados, lo cual explica su permanencia. La normativa impuesta por las Administraciones en España obliga a que la recolección de las plantas más vulnerables se realice mediante autorización previa, como sucede con el árnica, la genciana, la santolina y otras, en algunas regiones. Aunque la mayor parte de estas plantas siguen siendo utilizadas en forma silvestre, y sólo algunas sean objeto de cultivo en los huertos familiares, el efecto de la globalización ha empujado, por un lado, a la recolección intrusiva que rompe con la tradicional recolección a escala, y, por otro lado, la explotación con fines comerciales de las plantas que cuentan con una demanda comercial notoria, a menudo con destino a la exportación ${ }^{32}$. Esta exportación, tanto de plantas silvestres como cultivadas, puede reportar un importante movimiento económico, como sucede con la lavanda francesa, la salvia croata o el tomillo español.

El conflicto que se suscita con el acceso empresarial a estos conocimientos tradicionales se agranda comprendiendo que, a su vez, las comunidades locales que se valen de los mismos, por definición imprecisos, tampoco podrían privatizarlos, al desconocer cuáles son las fronteras de su particularidad. De hecho, muchos de estos conocimientos, más que particulares son generales, y por razones de mera difusión histórica han terminado siendo patrimonio de muchos o de todos. A sensu contrario, tampoco las corporaciones empresariales estarían en condiciones de privatizar es-

32 Vid. la regulación que se establece frente a la expoliación y la exportación, a propósito del patrimonio inmaterial, en el art. 5 de la Ley 10/2015, de 26 de mayo, para la salvaguardia del Patrimonio Cultural Inmaterial. 
tos conocimientos, aunque el hecho se presente con más frecuencia de la que cabría esperar. Las semillas, las raíces, los bulbos, los tallos, las cortezas, las hojas, las flores y los frutos de las plantas que nutren los herbolarios, o los servicios que en forma de conocimientos homeopáticos se venden parapetados tras las correspondientes marcas registradas destinadas a las farmacias y a las parafarmacias, generan suculentos beneficios que, sin embargo, no contribuyen al desarrollo local de las comunidades rurales. En los últimos años se han documentado numerosos casos de biopiratería, en los que importantes empresas se han apropiado del beneficio de la biodiversidad y de los conocimientos de las comunidades locales sobre las plantas, para convertirlos en bienes y servicios destinados a la explotación comercial por parte de la industria farmacéutica, la perfumera, la cosmética, la condimentaria y otras.

La biopiratería, esto es, la apropiación de los recursos biológicos y de los conocimientos asociados a ellos, sin un consentimiento informado previo, y la explotación económica de los mismos sin compensación para las comunidades humanas que los albergan, constituye un riesgo general, tal como ha mostrado V. Shiva reiteradamente $^{33}$, y como han probado recientemente T. Efferth y colaboradores ${ }^{34}$ Son casos conocidos los de las especies locales de plantas cultivadas (como el de los frijoles mexicanos Enola, por ejemplo) que han acabado privatizadas por empresas del ramo 35 , o los casos de empresas farmacéuticas como Novartis (Sandoz y Giba-Geigy) en relación con la explotación de los códigos genéticos de varias plantas de uso milenario. Muy citado resulta el caso de la empresa Monsanto, a propósito de la posesión de patentes sobre numerosas especies cultivadas, que incluyen el algodón, la mostaza, la soja, etc. De gran interés, asimismo, son los casos que refiere P. Schuler ${ }^{36}$, en relación con las patentes obtenidas en Estados Unidos, en 1992 y en Europa en 1994 respectivamente, por ejemplo, a cuenta de la margosa de la India y de los conocimientos asociados a la misma como fungicida, considerando que, aunque la patente europea fue revocada años más tarde, la norteamericana sigue en vigor. Aunque la nómina de casos similares a los que se acaban de mostrar es muy dilatada, en todos ellos las patentes se obtuvieron sobre productos derivados de conocimientos tradicionales.

Un caso más sorprendente aún fue el de la ayahuasca de América del Sur, que obtuvo patente como planta medicinal en los Estados Unidos en 1985, a solicitud de un empresario, y que, a pesar de ser impugnada la misma en 1999, se halla en la actualidad plenamente vigente tras una larga batalla judicial. Pero los casos se multiplican y alcanzan a la explotación con fines comerciales de empresas relacionadas con la biotecnología, especialmente en lo que interesa a sectores como el culinario-dietético, el farmacéutico, el químico, el cosmético, y otros. Algunas grandes empresas biotecnológicas han optado por la firma de contratos con entidades representativas de las comunidades locales para obtener la explotación de determina-

33 Shiva, 2001: 75-85; y Shiva, 2003: 51.

34 Efferth et al., 2016.

35 Ribeiro, 2005: 83-84; Nair, 2005

36 Schuler, 2004. 
das plantas, incluyendo los conocimientos y los usos sobre las mismas. Otros casos con gran repercusión internacional fueron, hace algunos años, el de la farmacéutica Merck en Costa Rica ${ }^{37}$, o el de la corporación empresarial Body Shop en relación con los kayapó de Brasil ${ }^{38}$.

De lo dicho se deduce que la protección del patrimonio cultural, por lo que se refiere a conocimientos y actividades es insuficiente, hasta el punto de que ha sido necesario avanzar en el ámbito de la protección del patrimonio inmaterial, siguiendo las directrices de la UNESCO. Existe un profundo debate en todo el mundo acerca de las políticas aplicables a la protección de los conocimientos tradicionales ambientales, que, si bien alcanzan su máxima intensidad con referencia a los pueblos indígenas, y constituyen buen ejemplo los casos de Argentina ${ }^{39}$, de Ecuador ${ }^{40}$, de Brasi $^{41}$ y de los países de América Latina en general ${ }^{42}$, el mismo no es ajeno al caso de sociedades como la nuestra. De hecho, la biopiratería encuentra su mejor aliado en el vacío legal que, a menudo, acompaña la explotación de estos conocimientos y actividades. En el caso de las sociedades indígenas se ha invocado frecuentemente, a favor de éstas, la defensa de los derechos humanos ${ }^{43}$, al entender que estos conocimientos tradicionales son inalienables, es decir, inseparables de las correspondientes concepciones culturales. En otras ocasiones se ha reclamado, asimismo, el derecho a las marcas colectivas y a las indicaciones geográficas ${ }^{44}$. Y, en todos los casos, se han demandado los derechos asociados a la propiedad intelectual, especialmente tras la entrada en vigor en 1995 del Acuerdo sobre los Derechos de Propiedad Intelectual (conocido por sus siglas en inglés como TRIPS) ${ }^{45}$, bien sea como derechos de autor, o bien lo sea como propiedad industrial (marcas, patentes, nombres comerciales, etc.).

Ahora bien, tales propuestas chocan con los conceptos, debido a que los derechos de autor, basados en la propiedad privada, son individuales, lejos del concepto de titularidad compartida que se reclama para los conocimientos tradicionales ${ }^{46}$. En cuanto a las figuras propias de la propiedad industrial (marcas, patentes y nombres comerciales, entre otros), parece difícil que los conocimientos consuetudinarios de las sociedades rurales puedan enmarcarse, por su amplitud, en alguna de estas modalidades. Con todo ello, la dificultad mayor es que estos conocimientos tradicionales han excedido con mucho el tiempo que permitiría considerarlos como privativos, de lo que, supuestamente, se seguiría su pertenencia al dominio público. Por todas estas razones, no son pocos los que vienen defendiendo la idea de que la única protección de tales conocimientos ambientales tradicionales estaría en un sistema

37 Vid. Reyes-García, 2009: 48-49.

38 Zimmerman et al. 2001: 19-20.

39 Endere y Mariano, 2013.

40 Donoso, 2007.

41 Zimmerman et al., 2001.

42 Coombe, 2016.

43 Silverman y Ruggles, 2007.

44 vid. en el caso de Brasil, Silva y Peralta, 2011.

45 Wüger, 2004; Nwabueze, 2013; Rodrigues Jr., 2014.

46 Hilty, 2009; Wong y Fernandini, 2010. 
sui generis, consistente en su inclusión en bases de datos, a salvo del acceso generalizado y de la apropiación indebida, simplemente mediante un procedimiento que consiste en proteger la base de datos en sí, lo cual permitiría la realización de un minucioso seguimiento científico y tecnológico de tales conocimientos ante el acoso de terceros. Recientes trabajos ponen de manifiesto la necesidad de preservar y proteger los conocimientos tradicionales mediante sistemas como el denominado TKDL (Traditional Knowledge Digital Library) de la India, el KTKP (The Korean Traditional Knowledge Portal) de Corea y el TCM (Chinese Traditional Medicine) de China, tal como explica el artículo de Lakshmi Poorna, Mymoon y Haharan ${ }^{47}$, aunque con la limitación propia de tratarse de sistemas que, en lo fundamental, recogen tan sólo los documentos escritos relativos al conocimiento tradicional de la medicina. A su lado, y en lo que se refiere al contenido del presente artículo, interesa especialmente el Proyecto Biozulua de Venezuela, destinado a compilar información no codificada u oral de los distintos grupos étnicos de la Amazonía, en materias como la medicina consuetudinaria indígena, la agricultura tradicional, y otras, con el fin de realizar en el futuro una protección sui generis de los contenidos de las bases de datos.

\section{La protección de los conocimientos tradicionales relativos a las plan- tas silvestres como patrimonio cultural y natural: el caso de España}

Evidentemente, y volviendo al caso de España, los conocimientos ambientales tradicionales, tales como los relativos a las plantas y sus usos son, por decirlo expresamente, comunales, es decir, pertenecen a la comunidad que habita un territorio. Sin embargo, a menudo, y debido a la evolución histórica, son conocimientos tan generalizados que resultan indiscernibles en su atribución. En consecuencia, no son privativamente de nadie, sino que las comunidades rurales, en su conjunto, serían depositarias de una tradición que hunde sus raíces en un tiempo indefinido. Estos conocimientos se derivan de una inveterada convivencia con las plantas silvestres representativas de los más variados ecosistemas ${ }^{48}$, las cuales han sido aprovechadas eficazmente por parte de las poblaciones locales. En un país mediterráneo como España, y con una incidencia variables en los distintos ecosistemas, han tenido mucha importancia los conocimientos aplicados a las plantas medicinales, tales como el equiseto (Equisetum arvense), la consuela (Symphytum officinale), la efedra (Ephedra fragilis), el hinojo (Foeniculum vulgare), la malva (Malva sylvestris), la manzanilla (Chamomelum nobile), el té silvestre (Jasonia glutinosa), el espino blanco (Cratoegus monogyna), el árnica (Arnica montana), la genciana (Gentiana lutea), el malvavisco (Malva sylvestris), la mejorana (Teucrium polium), la salvia (Salvia lavandulifolia), la valeriana (Valeriana officinalis), el tomillo (Thymus zygis), la ruda (Ruta montana), el poleo (Mentha pulegium) y otras. Asimismo, las poblaciones locales han heredado los conocimientos de las plantas condimentarias, como el orégano (Origanum vulgare), el hinojo (Foeniculum vulgare), el romero (Rasmarinus officinalis), el tomillo

47 Lakshmi Poorna, Mymoon y Haharan, 2014: 1241-1245.

48 Vid. Pardo de Santayana, Morales, Aceituno y Molina, 2014. 
(Thymus vulgaris), el enebro (Juniperus communis), etc. Igualmente, estas comunidades rurales han recibido los conocimientos de las plantas silvestres aromáticas, como el romero (Rosmarinus officinalis), el anís (Pimpinella anisum), el espliego ( $\mathrm{La}$ vandula latifolia), la salvia (Salvia lavandulifolia), la hierbabuena (Mentha spicata) y las distintas variedades de tomillo, entre otras más.

El uso y aprovechamiento de cada una de estas plantas requería minuciosos conocimientos, relativos a la recolección, al hervido, a la cocción, al macerado, a la fermentación, a la destilación y a otros procedimientos destinados a su aplicación, que en ocasiones han sido olvidados debido al proceso de cambio social que ha tenido lugar en la España rural. El aprovechamiento de las plantas, basado generalmente en el uso para el consumo doméstico, garantizaba la conservación de las mismas, gracias a que en las recolectas se preservaban los ejemplares aptos para la reproducción. El aprecio que suscitaban las aplicaciones de las plantas, destinadas a los humanos y a los animales, obligaba a extremar lo que ahora denominamos principio de precaución, en aras de la sostenibilidad de las plantas, a veces mediante complejos procesos, como el que permitía el aprovechamiento de la genciana (Gentiana lutea) en las comunidades rurales de montaña del norte de España. Dado que se trataba de una planta muy valorada por las cualidades medicinales de sus raíces, y que éstas necesitan un largo período de regeneración, por lo regular cercano a los diez años, los asentamientos rurales que compartían montes comunales se organizaban para realizar el aprovechamiento respetuoso de unas plantas que, además de ser estimadas en el ámbito doméstico, podían ser objeto de comercialización. El éxodo rural de mediados del siglo XX y el surgimiento de otros modos de vida acabó en muchos lugares con un conocimiento del medio y de los usos de la genciana que hoy se lamenta. El cambio social constituye también la explicación del olvido progresivo de la recogida del árnica (Arnica montana) y de los conocimientos asociados a esta planta en la cordillera Cantábrica, al cual ha seguido un largo período de recolectas indiscriminadas, ajenas a su aprovechamiento tradicional, que explican su vulnerabilidad actual. Ocasionalmente, puede suceder que la causa de que una especie silvestre se halle en riesgo de extinción resida en una sobrevaloración de la misma por parte de sus tradicionales usuarios, generalmente trascendiendo sus cualidades más evidentes. Éste es el caso de la llamada manzanilla real, la Artemisia granatensis de Sierra Nevada, que a partir de los años finales del siglo XIX es sometida a presiones crecientes, y un tanto inesperadas, por parte de las poblaciones serranas de Granada y Almería, que, corriendo el tiempo, y también por razones de cambio social, se vería reforzada con el efecto de una comercialización modesta. El hecho de que se trate de una planta que ocupa hábitats marginales, en los que concurren además de las circunstancias enunciadas otras de muy variado signo, ha reducido la presencia de esta planta a la mínima expresión. Estos ejemplos nos muestran cómo los procesos de cambio social y los usos no sostenibles de las planas silvestres, en concurrencia con las externalidades de muy variado signo, han provocado efectos muy negativos sobre la conservación de los ecosistemas. 
Antes del último cuarto del siglo XX no existió en España una preocupación generalizada por la protección de los conocimientos y usos de carácter tradicional, tanto porque no se les había concedido la relevancia que realmente poseían como porque aun conservaban cierta vitalidad y no existía la conciencia de una pérdida irremediable. El cambio de tendencia que se produce a partir de entonces da lugar a que en la Ley 16/1985 del Patrimonio Histórico Español se incluya un apartado consagrado al llamado patrimonio etnográfico, formado por "los bienes muebles e inmuebles y los conocimientos y actividades que son o han sido expresión relevante de la cultura tradicional del pueblo español en sus aspectos materiales, sociales o

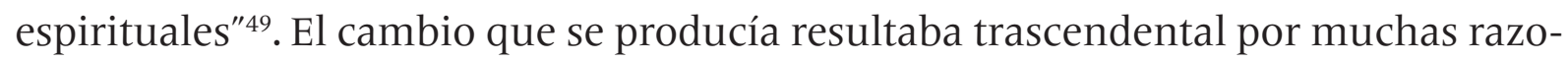
nes. En primer lugar, porque se superaban los criterios de historicidad y de belleza que habían regido hasta entonces el patrimonio para alcanzar otros que hacían referencia a la riqueza y a la idiosincrasia cultural de la vida de los pueblos. En segundo lugar, porque se trascendía la protección de los bienes-cosa que había caracterizado en el pasado al patrimonio histórico para irradiar a los bienes-actividad, entre los cuales iban a quedar incluidos los conocimientos ambientales que nos ocupan en el presente artículo.

En este sentido, y a modo de ejemplo, es bien evidente que nadie imaginó décadas atrás que los conocimientos ambientales tradicionales, y entre ellos los relativos al conocimiento y al uso de las plantas, pudieran formar parte, en pie de igualdad con los monumentos histórico-artísticos, del conjunto del patrimonio cultural, y, sin embargo, los primeros constituyen la valiosa herencia conservada aún por un sector de la sociedad, al cual en el pasado se le negó su contribución a la construcción de dicho patrimonio. Nadie estaría, asimismo, en condiciones de negar que estos conocimientos medioambientales encierran un patrimonio inmaterial plenamente acorde con el principio del desarrollo sostenible y, más aún, que los mismos remiten por igual al patrimonio natural y al patrimonio cultural. Para que tanto cambio haya sido posible, especialmente en las últimas décadas del siglo XX y en los años transcurridos del XXI, en el contexto de lo que A. Ariño ${ }^{50}$ ha denominado como las paradojas de la posmodernidad, en alusión a la creciente e incesante patrimonialización de la cultura, ha sido necesario, antes que nada, que fraguara una filosofía sensible, pero también vigorosa, en las instituciones internacionales, $y$, por efecto de éstas, en las nacionales. Y, además, ha sido necesario que se produjeran cambios doctrinales que permitieran encauzar normativamente lo que durante mucho tiempo había sido un mero deseo: la protección, a título de salvaguardia, de la cultura inmaterial o intangible, antes denominada espiritual en nuestra tradición.

Ahora bien, en la Ley 16/1985 no se hacía mención expresa del concepto de patrimonio inmaterial stricto sensu, sino que se optó por remitir a su contenido, acaso como mejor prueba de las dudas que suscitaba la obligación de prestar amparo a un patrimonio tan extenso y tan difuso como es el concerniente a "conocimientos o

49 Ley 16/1985, de 25 de junio, del Patrimonio Histórico Español, art. 46.

50 Ariño, 2012. 
actividades que procedan de modelos o técnicas tradicionales utilizados por una determinada comunidad"51. En cualquier caso, se habían sentado las bases para el logro de un objetivo ambicioso. Cuando la citada ley dé pábulo a que, en los años posteriores, los territorios autónomos del Estado promulguen su propia legislación, se verá cómo el patrimonio histórico se convierte paulatinamente en cultural, y cómo el patrimonio inmaterial pasa a rotular explícitamente las leyes relativas a este patrimonio cultural. Es importante decir, no obstante, que el patrimonio inmaterial adoleció desde el principio de un régimen jurídico insuficiente ${ }^{52}$. La razón estribó en la dificultad para proteger algo que no se encuadraba en los bienes propios del Código Civil, esto es, ni en los muebles ni en los inmuebles, que son materiales, con la consiguiente imposibilidad para extender el régimen de las cosas a las actividades. Es evidente que los bienes inmateriales corresponden a una categoría distinta, para la cual el legislador halló desde el principio un régimen jurídico particular, consistente en hacer previsión de la defensa de este patrimonio, denominado cada vez con más insistencia inmaterial o intangible, mediante el encargo a la Administración de su custodia, y ello valiéndose de la encomienda que comporta el registro e inventariado de cuantos conocimientos y actividades se hallen en previsible peligro de desaparición. Dicho de otro modo, la Administración se obliga a dotar de soporte material, analógico o digital, de acuerdo con el estado de la tecnología en ese momento, a cuantos bienes del patrimonio inmaterial estén amenazados de pérdida, o a aquéllos cuya pérdida haya sido tan reciente que aún sea posible el registro. Es bien manifiesto que mientras el patrimonio material se protege mediante la conservación, el inmaterial se protege a través de la salvaguardia.

También es preciso añadir que, por vía de los acuerdos internacionales, ha sido la Convención para la Salvaguardia del Patrimonio Cultural Inmaterial de 2003 la que ha ejercido una influencia determinante sobre las legislaciones de los Estados en materia de patrimonio inmaterial, de manera análoga a como lo hizo en 1972 Convención sobre la Protección del Patrimonio Mundial, Cultural y Natural a una escala distinta. La Convención para la Salvaguardia del Patrimonio Cultural Inmaterial ha perfilado, de una manera precisa, los contenidos del patrimonio inmaterial, los cuales se concretan de la siguiente manera ${ }^{53}$ : a) tradiciones y expresiones orales, incluido el idioma; b) artes del espectáculo; c) usos sociales, rituales y actos festivos; d) conocimientos y usos relacionados con la naturaleza y el universo; e) técnicas artesanales tradicionales. En lo que concierne al presente texto, el apartado d) condensa el ámbito específico del patrimonio inmaterial que más nos interesa a propósito de los conocimientos ambientales. Sin embargo, nótese que los conocimientos y usos relacionados con naturaleza precisan de un componente material indispensable (las plantas, los animales, el paisaje, etc.), a pesar de que hayamos recurrido a la fácil y convencional simplificación de separar el patrimonio material y el inmaterial, los

51 Ley 16/1985, de 25 de junio, del Patrimonio Histórico Español, art. 47.

52 Vid. Alegre, 2012.

53 Convención para la Salvaguardia del Patrimonio Cultural Inmaterial, 2003, art. 2. 
cuales son indisolubles desde todo punto de vista, tal como manifestaba hace poco tiempo N. Kaufman ${ }^{54}$ cuando reclamaba la unidad indisoluble del patrimonio material y del inmaterial por razones analíticas. Se deduce, en consecuencia, que la otra reducción que hemos realizado ha consistido en segregar el patrimonio natural y el cultural de manera espuria, cuando ambos son parte de una herencia que hemos recibido en forma de indiviso.

Las reflexiones precedentes nos ayudan a comprender la reciente promulgación de la Ley 10/2015 para la salvaguardia del Patrimonio Inmaterial ${ }^{55}$ que, en su preámbulo, pone el acento, justamente, en lo que es sustancial a propósito del patrimonio cultural, esto es, su fuerte componente simbólico, por un lado, y la marcada imbricación de lo material y lo inmaterial por otro lado. Ahora bien, es obvio que, así como en el patrimonio material prima lo tangible, en el patrimonio inmaterial domina lo intangible, de modo que su protección es más compleja, lo cual explica que se sustancie en la salvaguardia. La ley pretende fijar un concepto básico y general del patrimonio inmaterial, consistente en determinar los principios y derechos fundamentales implicados en este patrimonio, previendo la elaboración de un Inventario General del Patrimonio Cultural Inmaterial ${ }^{56}$, y la regulación de los instrumentos operativos de actuación, a través de un Plan Nacional de Salvaguardia del Patrimonio Cultural Inmaterial ${ }^{57}$. Además, la Ley 10/2015 incorpora una nueva técnica de protección, siguiendo la pauta de la Convención del Patrimonio Inmaterial de 2003 y su listado de bienes inmateriales amenazados, que se refiere a los casos de los bienes inmateriales que requieren medidas urgentes de salvaguardia, y que se resumen en la inclusión de los mismos, tanto no protegidos como insuficientemente protegidos, en una Lista de bienes del patrimonio inmaterial en peligro ${ }^{58}$, al menos en tanto no se produzca la necesaria acción ordinaria de protección. Pensando en un patrimonio como el que nos ocupa, esta técnica contribuirá a paliar la pérdida efectiva de conocimientos y de prácticas ambientalistas, y concretamente referidas al uso de las plantas medicinales, aromáticas, condimentarias, tintoreras, combustibles, ornamentales, etc., que se viene produciendo debido a la ruptura de la transmisión intergeneracional.

Los conocimientos y los usos relativos a las plantas constituyen unos bienes culturales tan valiosos que han motivado una normativa protectora que trasciende con creces el ámbito del patrimonio cultural para alcanzar al del patrimonio natural, como exponente de la indisolubilidad de los mismos. El Convenio de Naciones Unidas sobre la Diversidad Biológica de 1992, que entró en vigor a finales de 1993, y

54 Kaufman, 2013.

55 Ley 10/2015, de 26 de mayo, para la salvaguardia del Patrimonio Cultural Inmaterial.

56 Art. 14 de la Ley 10/2015.

57 Art. 13 de la Ley 10/2015. El actual Plan Nacional de Salvaguardia del Patrimonio Cultural Inmaterial fue redactado en 20011 . Este plan tendrá una vigencia de 10 años, y será revisable a los cinco años (art. 13 de la Ley 10/2015). Sin embargo, la ley (disposición transitoria única) obliga a que, tras la promulgación de la misma se elabore un nuevo Plan Nacional de Salvaguardia del Patrimonio Cultural Inmaterial en el plazo máximo de tres años.

58 Art. 5 de la Ley 10/2015. 
que constituye un protocolo internacional de la máxima relevancia, firmado por 196 partes contratantes, reconoce en su preámbulo la dependencia que tienen las poblaciones locales de los recursos biológicos, aprovechados en todo el mundo en mayor o menor medida, y la contribución de las mismas a la sostenibilidad ambiental y a la diversidad biológica, al tiempo que reclama un reparto justo y equitativo de los beneficios generados por este aprovechamiento. El Convenio obliga a las partes contratantes a velar por la preservación de las prácticas de las comunidades locales que entrañen estilos tradicionales de vida pertinentes para la conservación y la utilización sostenible de los recursos biológicos, equiparando en este uso a las comunidades locales y a las comunidades indígenas (lo cual habilita el establecimiento de algunas de las analogías que se realizan en este artículo), al tiempo que compromete a los Estados en la tarea de alentar la utilización consuetudinaria de todas aquellas prácticas culturales que resulten compatibles con la conservación de la biodiversiad ${ }^{59}$.

A la zaga de la preocupación existente en todo el mundo por la situación del patrimonio natural y la biodiversidad, se produjo la Directiva 92/43/CEE, del Consejo Europeo, relativa a la conservación de los hábitats naturales y de la fauna y la flora silvestres. Esta importante directiva, traspuesta a los derechos de todos los países de la Unión Europea, incluye la protección de numerosas especies silvestres, que en lo que se refiere a la flora se plasma en un Anexo $V$ de especies de interés comunitario cuya recogida y explotación pueden ser objeto de gestión a partir de ese momento. Además, en España existe una abundante legislación protectora del patrimonio natural, la cual se resume en la Ley 42/2007 del Patrimonio Natural y de la Biodiversidad, actualizada mediante la Ley 33/2015 con el objetivo de mejorar algunos aspectos derivados de su aplicación, particularmente en lo concerniente a la gestión de los espacios protegidos. Pues bien, una de sus novedades reside en el desarrollo que adquiere la promoción de los conocimientos tradicionales para la conservación del patrimonio natural y la biodiversidad ${ }^{60}$.

Así, la Ley 42/2007 del Patrimonio Natural y la Biodiversidad hace descansar la política de promoción de los conocimientos tradicionales sobre los llamados Inventarios de los Conocimientos Tradicionales ${ }^{61}$, que, a su vez, se integrarán en el Inventario Español de los Conocimientos Tradicionales relativos a la biodiversidad, tal como se adelantaba en el Real Decreto 556/201 $1^{62}$. La importancia de la actualización contenida en la Ley 33/2015 se halla en que, de este modo, la norma se alinea con las resoluciones y los principios del Convenio de las Naciones Unidas sobre Diversidad Biológica acordados en la Cumbre de Río (1992), y con los de la Organización Mun-

59 Convenio de Naciones Unidas sobre la Diversidad Biológica, 1992, art. 10.

60 Art. 74 de la Ley 42/2007 consolidada (antiguo artículo 70 de esta misma ley, antes de su modificación mediante la Ley 33/2015). El inciso 1.a responsabiliza a las Administraciones Públicas del fomento de los conocimientos y las prácticas de utilización consuetudinaria que sean de interés para la conservación y el uso sostenible del patrimonio natural y la biodiversidad.

61 Vid. Pardo de Santayana, Morales, Aceituno y Molina, 2014 (primera fase).

62 R. D. 556/2011 para el desarrollo del Inventario Español del Patrimonio Natural y la Biodiversidad. 
dial de la Propiedad Intelectual. Simultáneamente, la norma se ajustaba a los compromisos adquiridos por España, como Estado parte, en el protocolo de Nagoya, firmado en 2012, en todo lo concerniente al uso y conservación de los conocimientos tradicionales asociados a la biodiversidad. En suma, es evidente que estamos ante un patrimonio de índole natural que, por efecto de los procesos antrópicos, presenta otra dimensión de índole cultural, de suerte que ambas resultan indisociables.

La orfandad de régimen jurídico que parece descubrirse en todo lo concerniente a los bienes de carácter etnográfico, tanto muebles como inmuebles, en la Ley 16/1985 del Patrimonio Histórico Español, resulta aún más notoria en lo concerniente al patrimonio inmaterial. Ciertamente, esta carencia sólo resultó paliada por vía de la custodia que la Administración debía otorgar a cuantos conocimientos y actividades corrieran el riesgo de desaparecer mediante su documentación científica. Es obvio, sin embargo, que esta dimensión del patrimonio se cargó de fuerza tras la conversión de España en Estado parte de la Convención para la Salvaguardia del Patrimonio Inmaterial, celebrada a expensas de la UNESCO en 2003, cuando la documentación del patrimonio inmaterial fue elevado a la máxima consideración, previendo para ello una panoplia de instrumentos descriptivos guiados por la necesidad de investigar, preservar, proteger, valorar y transmitir este patrimonio inmaterial. Ahondando en las medidas adoptadas por la citada convención, la Ley 10/2015 para la salvaguardia del Patrimonio Cultural Inmaterial ha terminado por convertir el llamado Inventario General del Patrimonio Cultural Inmaterial ${ }^{63}$, junto al Plan Nacional de Salvaguardia del Patrimonio Cultural Inmaterial, en un instrumento primordial de la defensa de todos aquellos bienes englobados en la rúbrica de conocimientos y actividades, a riesgo de constituir una tarea inabarcable.

Más aún, la legislación dirigida a la defensa del patrimonio natural ha desplegado, complementariamente, una estrategia protectora de los conocimientos tradicionales acerca de las plantas, entendidos éstos como patrimonio cultural, de lo cual son buen ejemplo los Inventarios de Conocimientos Tradicionales previstos en la la Ley 42/2007, que ha venido a converger con la estrategia implementada, a su vez, por la normativa del patrimonio cultural. De este modo, la ley constituye una respuesta certera al riesgo de pérdida propio de unos conocimientos que representan la garantía de la conservación y uso sostenible del patrimonio natural, al tiempo que tutela los potenciales derechos de propiedad intelectual e industrial que se derivan de tales conocimientos. Tanto es así que, por su parte, la Ley 10/2015 para la salvaguardia del Patrimonio Cultural Inmaterial, a la vez que protege el patrimonio inmaterial protege el patrimonio material que le es inherente, alcanzando la protección a los espacios, a los lugares, a los itinerarios y a los soportes materiales en general, y recurriendo para ello, llegado el caso, a la legislación urbanística y a la relativa a la ordenación del territorio, entre otras ${ }^{64}$.

63 Artículo 14 de la Ley 10/2015.

64 Artículo 4.1 de la Ley 10/2015. 
La progresiva valoración social atribuida a estos conocimientos tradicionales parece explicar el interés en su defensa. Es evidente, sin embargo, que se trata, en cualquier caso, de una protección a título de salvaguardia, aun reconociendo el despliegue de un creciente celo protector. Ahora bien, podríamos preguntarnos si esta convergencia de normas orientadas al mismo objetivo no deviene en interferencia. La respuesta es que, más bien, estamos ante un reforzamiento del ordenamiento jurídico dirigido a la defensa de este bien cultural, si se tiene en cuenta el mandato del artículo 46 de la Constitución Española que obliga a todos los poderes públicos a la conservación del patrimonio cultural. Es obvio que la salvaguardia del patrimonio inmaterial, a efectos de los usos y conocimientos tradicionales de las plantas, no quedaría garantizada si no se protegiera el patrimonio natural, esto es, las plantas mismas. En este sentido, el Real Decreto 139/201165 contiene el Listado de Especies Silvestres en Régimen de Protección Especial y el Catálogo Español de Especies Amenazadas, un completo instrumento que lista la totalidad de los taxones o poblaciones correspondientes a especies amenazadas (tanto vegetales como animales, aunque aquí nos estemos refiriendo a las primeras), a las que clasifica en especies en peligro de extinción y en especies vulnerables. Por su parte, la Ley 42/2007 del Patrimonio Natural y la Biodiversidad garantiza la conservación de las especies autóctonas silvestres, gracias a instrumentos como el Listado de Especies Silvestres en Régimen de Protección Especial ${ }^{66}$, a la vez que obliga a las Comunidades Autónomas a adoptar las medidas necesarias para la conservación de la biodiversidad de carácter silvestre mediante los correspondientes planes de actuación ${ }^{67}$, de los que se siguen prohibiciones, limitaciones y otras medidas adicionales.

Ciertamente, todas las Comunidades Autónomas, en el uso de las competencias, previstas en el artículo 149.1.23 del texto constitucional en materia medioambiental, cuentan con Catálogos de Especies Amenazadas, que no son sino el resultado de desarrollar la normativa básica del Estado. Es la autonómica una normativa prolija y funcional que, en ocasiones, ni siquiera está anclada en la Ley 42/2007 sino que, aun hallándose plenamente vigente, se inspira en la precedente y derogada Ley 4/1989 de Conservación de los Espacios Naturales, reconociendo categorías de amenaza ajenas a las dos categorías que son propias de la normativa estatal vigente: vulnerable y en peligro de extinción ${ }^{68}$. De esta manera, y por lo que atañe al presente artículo, por vía de la catalogación autonómica de especies de flora amenazadas, y por mostrar algunos ejemplos relativos a las plantas más habituales de recolecta, se han visto protegidos taxones y poblaciones que no se hallan, a nivel estatal, en la Relación de

65 R. D. 139/2011, Anexo.

66 Artículo 53 de la Ley 42/2007 (consolidada).

67 Artículo 52 de la Ley 42/2007 (consolidada).

68 Así, por ejemplo, la Ley 4/2015 del Patrimonio Natural de Castilla y León (artículo 97), traza dos categorías de protección de las especies silvestres de Castilla y León: especies silvestres en régimen de protección especial y especies de atención preferente. Sin embargo, la vigente Ley 4/2006 (texto consolidado) de Conservación de la Naturaleza de Cantabria (artículo 48), traza los siguientes categorías de protección, dependiendo del grado o tipo de amenaza: extintas, en peligro de extinción, sensibles a la alteración de su hábitat, vulnerables y de interés especial. 
Especies incluidas en el Listado de Especies Silvestres en Régimen de Protección Especial y, en su caso, en el Catálogo Español de Especies Amenazadas, como sucede con las especies de recolecta, medicinales y aromáticas, acogidas a la figura de interés especial en Aragón ${ }^{69}$ : el acebo (Ilex aquifolium), el espino amarillo (Hypophaea rhamnoides), la genciana (Gentiana lutea), la hierba de Santa Rosa (Paeonia officinalis) y la oreja de oso (Ramonda myconi), y más recientemente ${ }^{70}$ la flor de nieve (Leontopodium alpinum).

Son, asimismo, de nuevo como ejemplo, los casos de las especies de recolecta consideradas como vulnerables por la normativa autonómica de Cataluña ${ }^{71}$, entre las que se encuentran, la flor de nieve (Leontopodium alpinum), el agracejo (Berberis vulgaris), el licopodio (Licopodium clavatum), el trébol de agua (Menyanthes trifoliata), la drosera (Drosera intermedia y Drosera angustifolia) o la salvia (Salvia valentina). Por su parte, la normativa autonómica de la Comunidad de Madrid ${ }^{72}$ cataloga como especies vulnerables de recolecta al acebo (Ilex aquifolium), al fresno común (Fraxinus excelsior), al tejo (Taxus baccata), al acónito (Aconitum napellus), al epilobio (Epilobium angustifolium) y al trébol de agua (Menyanthes trifoliata). Sin embargo, otras especies protegidas mediante distintas figuras jurídicas en la normativa autonómica han pasado a engrosar el listado estatal como especies en peligro de extinción, y éste puede ser el caso del tomillo sanjuanero (Thymus locosii), que aparece como especie en peligro de extinción en Aragón, y como especie vulnerable en Cataluña ${ }^{73}$ y en Navarra ${ }^{74}$. O también el caso del narciso (Narcissus pseudonarcissus), protegido por la normativa estatal como especie en peligro de extinción, y que ya se hallaba protegido con esta misma figura por la normativa de la Comunidad de Madrid $^{75}$. O es el caso de la genciana (Gentiana pneumonanthe y Gentiana angustifolia), protegida a nivel estatal como especie en peligro de extinción y que en Cataluña ${ }^{76}$ se halla protegida, igualmente, como especie en peligro de extinción.

La obligación de conservación del patrimonio natural que se explicita en la Ley 42/2007 del Patrimonio Natural y de la Biodiversidad es inseparable de la responsabilidad legal, de carácter administrativo, que concierne a los infractores de la misma, la cual no ciega las responsabilidades de orden civil o penal ${ }^{77}$, dejando a salvo, en todo caso, el principio non bis in idem. Reservado el derecho penal para las acciones u omisiones más graves, el derecho administrativo sancionador se convierte en el instrumento que garantiza el cumplimiento de esta ley, en rima con el artículo 45.3 de la Constitución Española, y de manera análoga a como lo hace la Ley 16/1985

69 Decreto 49/1995 de la Diputación General de Aragón (modificado parcialmente por el Decreto 181/2005 del Gobierno de Aragón).

70 Decreto 181/2005 del Gobierno de Aragón.

71 Resolución AAM/732/2015.

72 Decreto 18/1992.

73 Resolución AAM/732/2015.

74 Decreto Foral 94/1997.

75 Decreto 18/1992.

76 Resolución AAM/732/2015.

77 Artículo 79 de la Ley 42/2007 (consolidada) 
en relación con el artículo 46 del texto constitucional a propósito del patrimonio cultural $^{78}$. Tanto la normativa de conservación del patrimonio natural como la de conservación del patrimonio cultural tratan, por un lado, de cumplir con un propósito preventivo o disuasorio, y, en segundo lugar, de reparar el daño de acuerdo con la responsabilidad que atañe al infractor. También, tanto en el caso del patrimonio cultural como en el del patrimonio natural, ese derecho administrativo sancionador se entiende en el contexto del reparto de competencias, o de una concurrencia normativa, que alcanza al Estado y a las Comunidades Autónomas, con independencia de las competencias que tiene atribuidas en exclusiva el Estado, entre las cuales se hallan las de tratamiento general. Ahora bien, así como en la normativa del patrimonio cultural es frecuente la remisión a normas sancionadoras en blanco, en la del patrimonio natural el derecho sancionador muestra con toda su concreción el principio de tipicidad ${ }^{79}$ en la Ley $42 / 2007$, incluyendo las referencias precisas a las especies silvestres, y previendo las correspondientes sanciones, por acción o por omisión, a las cuales se añadirá el régimen sancionador que, en base a los principios de tipicidad y proporcionalidad, sea introducido por las Comunidades Autónomas.

La tipificación de las infracciones y de las sanciones que lleva aparejado el sistema normativo de conservación del medio natural (y que resulta indispensable para la salvaguardia de los conocimientos tradicionales sobre el mismo), no sería posible sin un aparato de vigilancia y de inspección, dependiente de las autoridades y agentes de la Administración autonómica, tales como agentes medioambientales, agentes forestales, celadores medioambientales y otros, así como de los agentes de la Guardia Civil (especialmente por los adscritos al SEPRONA), de otros Cuerpos y Fuerzas de Seguridad del Estado y de las policías locales, encargados de velar por el cumplimiento de la normativa, y obligados a denunciar, a los infractores, y a incautar y decomisar, en su caso, el producto de las acciones de estos últimos. Por su parte, la Fiscalía del Medio Ambiente posee, entre sus cometidos, el de ejercitar la acción pública en cualquier tipo de procedimiento relacionado con los daños medioambientales, y particularmente en los procesos penales. Las prohibiciones, las limitaciones y las medidas adicionales a las que están sometidas las intervenciones en el medio natural determinan la existencia de reglas rigurosas que regulan, en lo que interesa al propósito de este texto, los aprovechamientos de las plantas silvestres, mediante categorías de protección que acompañan al Catálogo Regional de Especies Amenazadas. Tales prescripciones alcanzan el máximo rigor en el caso de las especies en peligro de extinción y en el de los espacios protegidos que se hallan normativamente establecidos: parques nacionales y parques naturales, reservas naturales, monumentos naturales, paisajes protegidos, etc.

Existen sobradas pruebas de la importancia que han tenido en las poblaciones rurales españolas los conocimientos y los usos relativos a las plantas, transmitidos a través del tiempo, y del papel que han jugado los mismos en la sostenibilidad

78 Vid. Amate Ávila, M. L., 2012: 34-45.

79 Artículo 80 de la Ley 42/2007 (consolidada). 
ambiental, social y económica del medio rural. Se trata de conocimientos asociados a plantas curativas, aromáticas, condimentarias y de todo tipo, por regla general silvestres, que han satisfecho las necesidades de estas poblaciones, gracias a que han sido aprovechadas evitando que resultaran esquilmadas. Sin embargo, un profundo proceso de cambio social ha terminado por trastornar los ecosistemas y por romper la cadena de trasmisión de los conocimientos tradicionales relativos a las plantas. En esta situación, los últimos lustros han conocido el afianzamiento de una conciencia social cada vez más comprometida con la conservación de la biodiversidad, y con la utilización de unos recursos naturales que no pongan en riesgo la satisfacción de las necesidades de las generaciones futuras, que hace del principio de precaución la norma fundamental del uso de la naturaleza. Los conocimientos tradicionales de las plantas, que hicieron posible la conservación de los más variados ecosistemas por parte de los habitantes de las áreas rurales en el pasado, deben contribuir en el presente a conjugar la conservación de los hábitats, incluidos los silvestres, con un desarrollo ambiental sostenible que devenga tanto en el bienestar general de la población como en una creciente participación pública en los asuntos medioambientales.

\section{Conclusión}

Las poblaciones rurales conservan, en mayor o menor medida, repertorios de conocimientos y prácticas medioambientales en general, y referidos a las plantas en particular, que, sin embargo, se hallan cada vez más mermados y en grave riesgo de desaparecer. Los movimientos migratorios hacia las áreas urbanas han supuesto el progresivo abandono del medio rural en muchos lugares, con la consiguiente ruptura de la cadena de transmisión entre generaciones. Por otro lado, la actividad agraria que definió al medio rural en el pasado ha dejado paso a la denominada nueva ruralidad, esto es, a nuevas formas de vivir y sentir el campo, caracterizadas por una creciente desvinculación del medio natural, y complementariamente de los conocimientos y las prácticas que fueron propias en otro tiempo de la vivencia en el medio rural. Esta pérdida se ha intensificado por efecto de una poderosa globalización que relega lo particular en beneficio de una imparable homogeneización cultural. Ha sido de este modo como han caído en el olvido los conocimientos relativos a la recogida, por ejemplo, de las plantas silvestres, y al uso tradicional de las sumidades de las mismas, de los tallos, de las cortezas, de las hojas, de los frutos, de las flores, de las semillas, de los bulbos, etc., que, a través del macerado, de la cocción, del hervido y de otros procedimientos permitían la elaboración de ungüentos, pomadas, bálsamos, infusiones y otros preparados. La experiencia acumulada por las poblaciones rurales, y el caso de nuestro país resulta bien expresivo, las hacía acreedoras de una loable pericia en el uso de las plantas con fines curativos, aromáticos, ornamentales, y de todo tipo, sin perder el horizonte del alto valor simbólico que les era atribuido a las mismas.

Los conocimientos tradicionales relativos a las plantas que se hallan en posesión de las comunidades rurales son el fundamento de una sostenibilidad milena- 
ria. La recolección de plantas silvestres, de acuerdo con conocimientos empíricos, sobradamente contrastados, contribuye a la fijación de poblaciones vegetales en su medio natural y al estímulo de la biodiversidad, convirtiéndose en uno de los fundamentos de la sostenibilidad ambiental que, en consecuencia, se conjuga con otras sostenibilidades, como la social y la económica. Así, el uso racional de estas plantas, basado en la tradición oral, ha evitado que fueran esquilmadas, permitiendo así que en todo momento quedara garantizado su aprovechamiento por parte de las generaciones posteriores, dando así pábulo a la teoría del desarrollo sostenible, tal y como la conocemos en el presente. Precisamente, la trascendental contribución que han realizado las comunidades rurales a un desarrollo sostenible mantenido en el tiempo constituye la prueba del derecho de las mismas a que sus conocimientos y prácticas no puedan ser objeto de apropiación por parte de terceros sin un consentimiento informado previo, y explica, asimismo, que, en el caso de que estos últimos fueran autorizados para usarlos, las primeras conservarían un derecho pleno de resarcimiento.

El hecho de que el conocimiento reunido por las comunidades locales sea tradicional y difuso estimula la maliciosa consideración de que pueda ser entendido como un dominio público, exento de titularidad por definición, de modo que su explotación no entrañaría obligaciones de restitución. Las estrategias empleadas hasta el presente en distintos países del mundo para hacer frente a la apropiación indebida por parte de terceros, han llevado a asimilar estos conocimientos y usos a los derechos humanos, a las marcas colectivas, de indicación geográfica por ejemplo, y a la propiedad intelectual, bien como derechos de autor o bien como derechos de la propiedad industrial, aunque los resultados que se han obtenido de esta lucha para hacer frente a la codicia de particulares sin escrúpulos han sido modestos por el momento. Ante esta compleja situación, se ha venido defendiendo insistentemente la idea de que la defensa efectiva de tales conocimientos ambientales tradicionales podría hallarse en un sistema sui generis, consistente en su inclusión en bases de datos protegidas, a salvo del acceso generalizado y de la apropiación indebida.

En las últimas décadas se han perfeccionado los instrumentos de protección de este vasto patrimonio. El hecho de estar compuesto por bienes intangibles impide que la protección se oriente a la conservación, de modo análogo a como se procedería en el caso de los bienes materiales, lo cual explica que se haya optado preferentemente por una acción de salvaguardia que, progresivamente ha redundado en la mejora de la tutela de estos bienes. Precisamente, en el caso de España, la insuficiencia de esta tutela que se advierte en el ordenamiento jurídico, ha sido paliada con la promulgación de la Ley 10/2015 para la salvaguardia del Patrimonio Inmaterial, sobre todo porque crea mecanismos de protección más precisos, como el Plan Nacional de Salvaguardia del Patrimonio Inmaterial, y como el Inventario General del Patrimonio Cultural Inmaterial. En este sentido, un instrumento de protección de primer orden, que abunda en esta misma dirección, incluso de una manera más precisa en relación con el tema de este artículo, es el Inventario Español del Patrimonio Natural y 
la Biodiversidad, nacido, en el marco de la Ley 42/2007 del Patrimonio Natural y la Biodiversidad, con el objeto de integrar los llamados Inventarios de los Conocimientos Tradicionales. Resulta evidente que estamos ante un patrimonio de índole natural, que como consecuencia de los efectos antrópicos, presenta, asimismo, un marcado carácter cultural, de suerte que ambos resultan indisociables. Esta normativa estatal, protectora por igual del patrimonio cultural y del natural, consecuente con los acuerdos internacionales, se ha complementado con otra, densa y prolija, emanada desde las Comunidades Autónomas, que alcanza, asimismo por igual, al patrimonio cultural y al patrimonio natural, lo cual constituye una prueba fehaciente de la preocupación que causa el riesgo de pérdida de este patrimonio.

\section{Bibliografía}

AMATE ÁVILA, María Luisa. La potestad sancionadora y sus especialidades en materia de patrimonio histórico. Revista ph. Boletín del Instituto Andaluz del Patrimonio Histórico, 2012, vol. 82, p. 34-45.

ARIÑO, VILLAROYA, Antonio. La patrimonialización de la cultura y sus paradojas postmodernas. In LISÓN TOLOSANA, C. (dir.). Antropología: Horizontes Patrimoniales Valencia: Tirant lo Blanch, 2012, p. 219-230.

ALEGRE ÁVILA, Juan Manuel. El patrimonio etnológico: un patrimonio cultural sin régimen jurídico". Revista ph. Boletín del Instituto Andaluz del Patrimonio Histórico, 2012, vol. 82, p. 83-99.

BERLIN, Brent: Ethnobiological classification: principles of categorization of plants and animals in traditional societies. Princeton (N.J): Princeton University Press, 1992.

CASTILLO RUÍZ, José y MARTÍNEZ YÁÑEZ, Celia. El patrimonio agrario: Definición, caracterización y representación en el ámbito de la UNESCO. Boletín de la Asociación de Geógrafos Españoles, 2014, vol. 66, p. 105-124.

COOMBE, Rosemary J. The knowledge economy and its cultures. Neoliberal technologies and Latin American. HAU: Journal of Ethnographic Theory, 2016, vol. 6 (3), p. 247-275.

CUISENIER, Jean. La tradition populaire. París. PUF, 1995.

DESCOLA, Philippe. Par-delà nature et culture. París. Gallimard, 2005.

DONOSO BUSTAMANTE, Sebastián Ignacio. Hacia la creación de un sistema sui generis para la protección de los conocimientos tradicionales en el derecho ecuatoriano. Iuris Dictio. Revista del Colegio de Jurisprudencia, 2007, vol. 7 (10), p. 95-111.

DREW, Joshua A. y HENNE, Adam P. Conservation biology and traditional knowledge: Integrating academic disciplines for better conservation practice. Ecology and Society, 2006, vol 11 (2), art. 34.

EFFERTH, Thomas et al. Biopiracy of natural prodicts and good bioprospecting practice. Phitomedicine, 2016, vol. 23 (2), p. 166-173. 
ENDERE, María Luz y MARIANO, Mercedes. Los conocimientos tradicionales y los desafíos de su protección legal en Argentina. Quinto Sol, 2013, vol. 17 (2), p. 1-20.

FRAZÄO-MOREIRA, Amélia, CARVALHO, Ana María y MARTINS, Maria Elisabete. "Conocimientos acerca de plantas en la nueva ruralidad. Cambio social y agro ecología en el Parque Natural de Montesinho (Portugal)”. Perifèria, 2007, vol. 7, $1-14$.

GÓMEZ PELLÓN, Eloy. Vida tradicional y proceso de cambio en un valle del Oriente asturiano. Oviedo: Trea, 1994

GÓMEZ PELLÓN, Eloy. Carmona. Patrimonio etnográfico y tradición cultural. Santander: Universidad de Cantabria, 1998.

GÓMEZ PELLÓN, Eloy. Ruralidad y discurso: del caso español al de Cantabria. AIBR. Revista de Antropología Iberoamericana, 2014, vol. 7 (3), p. 295-326.

GÓMEZ PELLÓN, Eloy. Aspectos teóricos de las nuevas ruralidades latinoamericanas. Gazeta de Antropología, 2015, vol. 31(1)/11, http://www.gazeta-antropologia. $\mathrm{es} / \mathrm{p}=4770$

GOODENOUGH, Ward H. Cultura, lenguaje y sociedad. In KAHN, J. S. (comp.). El concepto de cultura: Textos fundamentales. Barcelona: Anagrama, 1975 [1971], p. 157-248.

HILTY, Reno M. “Rationales for the legal protection of intangible goods and cultural heritage". IIC International Review of Intellectual Property and Competition Law, 2009, vol. 40 (8): 883-939.

KAUFMAN, Ned. Putting intangible heritage in its plácets: Proposals for policy and practice. International Journal of Intangible Heritage, 2013, 8, 19-36.

LAKSHMI POORNA, R., MYMOON, M. y HARIHARAN, A. Preservation and protection of traditional knowledge: diverse documentation initiatives across the globe. Current Science, 2014, vol. 107 (8), p. 1240-1246.

LLORENTE PINTO, José Manuel. Dehesas y paisajes adehesados en Castilla y León. Polígonos, 2011 , vol. 21, p. 79-203.

LÓPEZ PIÑERO, José María y LÓPEZ TERRADA, María Luz. La influencia española en la introducción en Europa de las plantas americanas (1493-1623), Valencia: Instituto de Estudios Documentales e Históricos sobre la Ciencia, 1998.

MÉNDEZ-BACETA, Gorka et al. Trends in wild food plants uses in Gorbeialdea (Basque Country). Appetite, 2017, vol. 112 (1), 9-16.

MOLINA, María et al. Exploring the potential o wild food resources in the Mediterranean region: natural yield and gathering pressure of the wild asparagus. Spanish Journal of Agricultural Research, 2012, vol. 4, 1090-1100.

MORALES VALVERDE, Ramón et al. Biodiversidad y etnobotánica en España. Memorias de la Real Sociedad Española de Historia Natural, 201 1, vol. 9, 157-207. 
NAIR, M.D. Traditional medicines and medicinal plants, and theri protection modalities from an intelectual property rights. Plant Genetic Resoruces: Characterisation and Utilisation, 2005, n³ (2), p. 314-319.

NWABUEZE, Caroline Joelle. The role of intellectual property in safeguarding intangible cultural heritage in museums, International Journal of Intangible Heritage, 2013, vol. 8, p. 181-190.

PARDO DE SANTAYANA, Manuel y GÓMEZ PELLÓN, Eloy. Etnobotánica: aprovechamiento tradicional de plantas y patrimonio cultural. Anales del Jardín Botánico de Madrid, 2003, vol. 60 ( 1), p. 171-182.

PARDO DE SANTAYANA, Manuel. Estudios Etnobotánicos en Campoo (Cantabria): conocimiento y uso tradicional de las plantas. Madrid: Consejo Superior de Investigaciones Científicas, 2008.

PARDO DE SANTAYANA, Manuel et al. Etnobiología y biodiversidad: el inventario español de los conocimientos tradicionales. Ambienta, 2012, vol. 9, p. 157-207.

PARDO DE SANTAYANA, Manuel. Etnobotánica e inventario español de conocimientos tradicionales. Conservación Vegetal, 2014, vol. 18, p. 1-4.

PARDO DE SANTAYANA, Manuel y MACÍA BARCO, Juan Manuel. Los beneficios del conocimiento tradicional sobre las plantas. Investigación y Ciencia, 2015, vol. 467, p. 12-13.

PARDO DE SANTAYANA, Manuel, PIERONI, Andrea y RAJINDRA K. Puri (Coords.). Ethnobotany in the new Europe: people, health, and wild plant resources, Berghahn: New York \& Oxford, 2010.

PARDO DE SANTAYANA, Manuel, MORALES, Ramón, ACEITUNO, Laura y MOLINA, María (Eds.) Inventario español de los conocimientos tradicionales relativos a la biodiversidad, Madrid: Ministerio de Agricultura, Alimentación y Medio Ambiente, 2014 (Primera fase).

PÉREZ DÍAZ, Antonio (2005): "Reflexiones en torno a la sostenibilidad de la dehesa". Geographicalia, 2005, 48, p. 101-120.

PÉREZ DÍAZ, Antonio. La dehesa: ¿un paisaje en agonía? Revista de Estudios Extremeños, 2015 vol. 71 (1), p. 569-604.

PIERONI, Andrea y SOUKAND, Renata. The disappearing wild food and medicinal plant knowledge in a few mountain villages of North Eastern Albania. Journal of Applied Botany and Food Quality, 2017, vol. 90, p. 58-67.

REYES-GARCÍA, Victoria. Conocimiento ecológico tradicional para la conservación: dinámicas y conflictos. Papeles, 2009, vol. 107, p. 39-55.

RIBEIRO, Silvia. ¿Qué pasó con la patente del frijol Enola? Ecología Politica, 2005, vol. 30, p. 85-86. 
RODRIGUES Jr., E. B. Using the TRIPS Agreement's unfair competition clause to curb the misappropriation of biological resources, traditional knowledge and expressions of folklore in user countries. Queen Mary Journal of Intellectual Property, 2014, vol. 4 (2), p. 139-155.

RUGGLES, D. Fairchild y SILVERMAN, Helaine. From tangible to intangible heritage. In RUGGLES, D. Fairchild y SILVERMAN, Helaine (eds.). Intangible Heritage Embodied. Champaign: University of Illinois at Urbana-Champaign, 2009, p. $1-14$.

SÁNCHEZ PONS, Jean Nöel "'Clavados con el clavo'. Debates españoles sobre el comercio de las especias asiáticas en los siglos XVI y XVII". In BERNABÉU ALBERT, S. y MARTÍNEZ SHAW, C. (Eds.), Un océano de seda y plata: el universo económico del Galeón de Manila. Madrid: CSIC, 2013, p. 107-132.

SANSANELLI, Sabrina y TASSONI, Annalisa. Wild food plants traditionally consumed in the área of Bologna (Emilia Romagna región, Italy). Journal of Ethnobiology and Ethnomedicine, 2014, vol. 10 (1), p. 10-69.

SHIVA, Vandana. Biopiratería. El saqueo de la naturaleza y del conocimiento. Barcelona: Icaria-Antrazyt, 2001 [1997].

SHIVA, Vandana. ¿Proteger o expoliar? Los derechos de propiedad intelectual. Barcelona: Intermon Oxfam, 2003 [2001].

SCHULER, P. Biopiracy and commercialization of ethnobotanical knowledge. In FINGER, M. y SHULER, P. (Eds.), Poor people's knowledge. Promoting intellectual property in developing countries. Washington: Wordl Bank y Oxford University Press, 2004, p. 159-181.

SILVA PÉREZ, Rocío.La dehesa vista como pasaje cultural:fisonomías, funcionalidades y dinámicas históricas, Ería, 2010, vol. 82, p. 143-157.

SILVA, E. F. Y PERALTA, P. P. "Collective marks and geographical indicationscompetitive strategy of differentiation and appropriation of intangible heritage", Journal of Intellectual Property Rights, 2011 , vol. 16 (3), 246-257.

SILVERMAN, Helaine y RUGGLES, D. Fairchild. Cultural heritages and Human Rights. In Silverman, H. Cultural Heritage and Human Rights. SILVERMAN, Helaine y RUGGLES, D. Fairchild (eds.). New York: Springer, 2007, p. 3-29.

TYLER, Stephen (ed.). Cognitive Anthropology. New York: Holt, Rinehart and Winston, 1969, p. 1 - 23.

VECCO, Marilena. A definition of cultural heritage: From the tangible to the intangible. Journal of Cultural Heritage, 2010, vol. 11 (3), p. 321-324.

WONG, Tzen y FERNANDINI, Claudia. Traditional cultural expressions: Preservation and innovation. In WONG, Tzen (ed.). Intellectual Property and Human Development: Current Trends and Future Scenarios. Cambridge: Cambridge University Press, 2010, p. 175-217. 
WÜGER, Daniel. Prevention of Misappropriation of Intangible Cultural Heritage through intellectual Property Laws. In FINGER, Michael \& SCHULER, Philip (eds.), Poor People's Knowledge, Promoting Intellectual Property in Developing Countries. Washington: Wordl Bank y Oxford University Press, 2004, p. 183-206.

ZIMMERMAN, Barbara, PEREZ, C. A., MALCOM, Jay R. y TURNER, T. Conservation and development alliances with the kayapó of south-eastern Amazonia, a tropical forest indigenous people. Environmental Conservation, 2001, vol. 28 (1), $10-22$.

(c) Copyright: ELOY GÓMEZ-PELLÓN, 2018

(C) Copyright Scripta Nova, 2018.

Ficha bibliográfica:

GÓMEZ-PELLÓN, Eloy. Sostenibilidad del medio rural y patrimonio inmaterial. A propósito de los conocimientos tradicionales de las plantas, Scripta Nova. Revista Electrónica de Geografía y Ciencias Sociales. [En línea]. Barcelona: Universidad de Barcelona, 15 de mayo de 2018, vol. XXII, nº 590. ISSN: 1138-9788. 